\title{
Automatic Train Track Monitoring and Collision Avoidance System
}

\author{
Saikat Srimani ${ }^{1}$, Rohit Majumdar ${ }^{2}$, Krishnashree Majhi ${ }^{3}$, Madhurendra Kumar ${ }^{4}$, \\ Tanusree Dutta ${ }^{5}$, Rabindranath Ghosh ${ }^{6}$ \\ U.G. Student, Dept. of ECE, St. Thomas' College of Engineering \& Technology, Kolkata, India ${ }^{1,2,3,4}$ \\ Assistant Professor, Dept. of ECE, St. Thomas' College of Engineering \& Technology, Kolkata, India ${ }^{5}$ \\ Professor, Dept. of ECE, St. Thomas' College of Engineering \& Technology, Kolkata, India ${ }^{6}$
}

\begin{abstract}
The most famous transportation system in India and abroad is the railway system. With rapid growth of locomotive systems in modern times the number of accidents happening all around the world is increasing day by day. Thus, there is a strong need for automatic train track monitoring to avoid collisions. This paper is concerning Automatic Train Track Monitoring and Collision Avoidance System. It adds up three new levels of safety, security and convenience to railway locomotive system. With this system installed and running every authorized person can get live information feed of the active railway tracks and the trains which are using it. If by any chance the supervisor at the control station makes any wrong decision which may lead to a collision, the automatic collision avoidance algorithm constantly checks and make sure no collision happens.
\end{abstract}

Keywords: NodeMCU, Collision Avoidance System, Hall Device, RFID, IoT

\section{INTRODUCTION}

India's first ever railway system proposal was made in Madras 1832. In the year 1853 railway was first introduced in India and it was adapted in whole country by 1951. Indian railway system is one of the most used locomotive systems in the world. With a population of 1.3 billion people India offers a huge number of trains. In 2017 India is the second on the list of countries by rail usage and on the third position on the list of countries having large railway network. In the recent years with the introduction of new high-speed rail models and with the big number of new rails deployed Indian railway system is getting more and more congested and more frequently we hear news of rail accidents. These accidents happen due to various reasons like inefficient track management, faulty brakes, human error, error in managing track crossing points, etc. From a national survey it is observed that during 2010-2015 out of a total of 803 accidents, 694 accidents were caused due to human failure. This paper seeks to develop a new safety system for railways which can provide safety to human lives and reduce accidents. The primary objective of our automatic train track monitoring and collision avoidance system is to check all the active trains, their current status and identify any potential threat ahead of time and to take action to prevent the collision from happening. In addition to that the system can also provide real time train tracking system information to the competent authority. The train tracking system is based on RFID technology. The system has been designed using NodeMCU microcontroller system with embedded ESP8266 Wi-Fi module to provide internet connectivity. The system is reliable and cost effective. It has also used Hall Effect Sensor to identify any small crack in the track and to secure the train accordingly. An online database has been created to store data from the sensors. Application Programming Interfaces (APIs) have been developed to make data storing and data retrieval process easy. An efficient algorithm has also been developed to identify and prevent collision from happening.

\section{LITERATURE SURVEY}

K. Ajith Theja et. al. [1] focused on preventing skilled workers to operate the railway crossing and established a model to open and close railway gate automatically using Wireless Sensor network (WSN) thus avoiding accidents caused by human errors.

Any M. Kottalil et. al. [2] proposed a tested circuit to control the opening and closing of railway gate precisely using ATMEGA 16 in order to reduce the problem of longer wait time for road passengers while waiting for passage of train. In [3], the authors proposed a model which provided the means for real time inspection and automatic gate control using IR sensors lessening the manual interference to avoid accidents occurring due to human negligence.

Sheikh Shanawaz Mostafa et. al. [4] proposed a method for avoiding collision by using radio links in order to transfer identification, information of approaching and outgoing trains faster to avoid accidents at railway crossing. 


\section{International Advanced Research Journal in Science, Engineering and Technology}

Vol. 6, Issue 5, May 2019

In [5], authors did a comparison of level crossings used across the world and aimed to embed railway crossings with automated platform bridges in order to provide automatic level crossing thus reducing the wait time due to opening and closing of gate irrespective of train arrival.

In [6] the authors proposed a solution encompassing GSM and GPS technologies to provide train tracking and pinpointing location of obstacles using GPS.

D. Karthiga Devi et. al. [7] implemented an autonomous system that uses image processing techniques to identify obstacle movement along the tracks thus focusing on preventing accidents caused due to obstacle collision.

\section{SYSTEM DESIGN}

The block diagram of the system for the automatic train track monitoring and collision avoidance system is shown in Fig .1

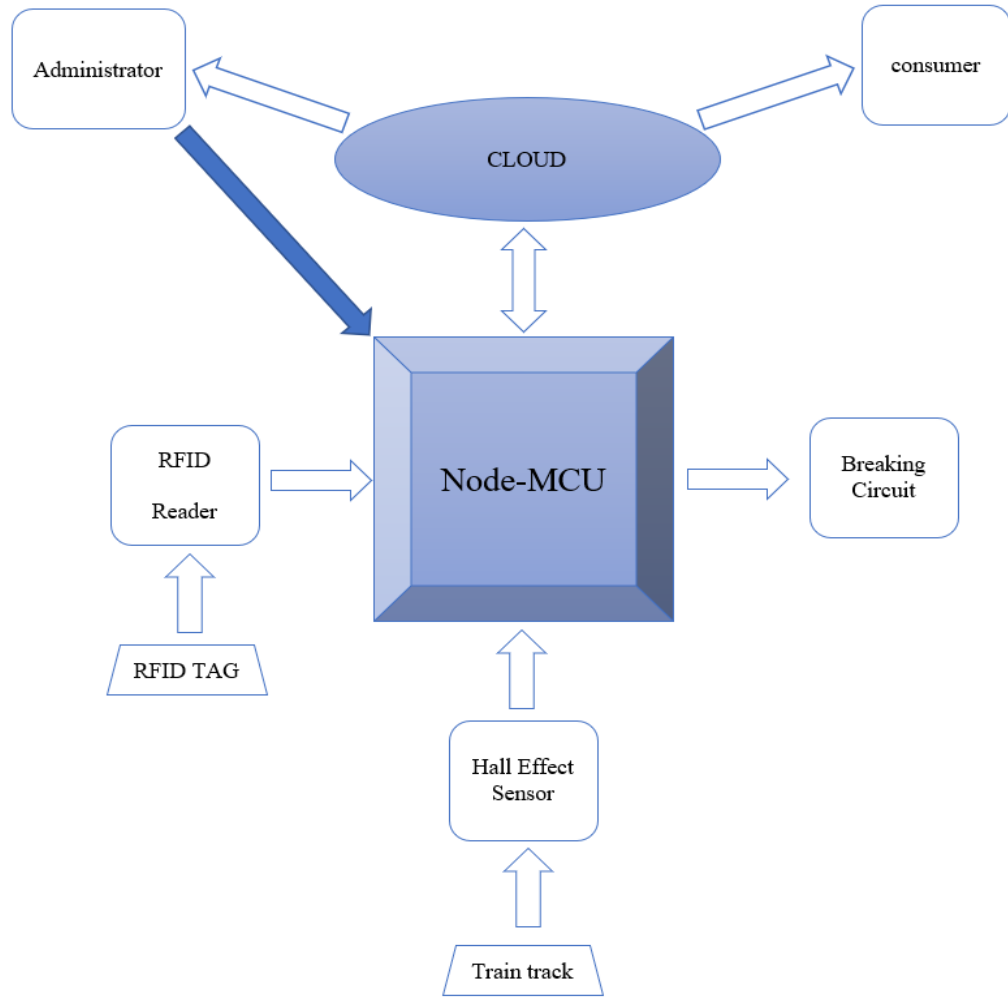

Fig. 1 Block diagram of the system

In the above block diagram the cloud consists of all the online components like databases, APIs, mobile App connectivity. The cloud will be communicating with the NodeMCU, Administer and consumer mobile app directly. The administrator is the only one capable of manually turning on and turning off this system of any particular train. The designing process consists of two parts: hardware design and software design. The hardware design is done by connecting the microcontroller, actuators and sensors in a distinct way. Software designing consists of designing databases, APIs, Mobile Apps to configure and manage data from hardware properly. The hardware components used are NodeMCU microcontroller, RFID Reader (MFRC522) and RFID tags, and Hall sensor (3144 EUA). NodeMCU is an open source firmware for the ESP8266 Wi-Fi system-on-chip (SOC). The MFRC522 is an RFID reader/writer working at $13.56 \mathrm{MHz}$ with speeds up to $848 \mathrm{Kbit} / \mathrm{s}$ in both directions. Apart from these there are some small hardware such as buzzer, motors and L293D motor driver ICs. Regarding Software design, an online server is used to make all data stream flow easily and securely. 000webhost online free server has been used in the model. It generally keeps the database and APIs online and running smoothly. PHP5 database has been constructed as shown in Figures 3, 4 and 5. A number of APIs have been used to store, retrieve, manipulate, and delete data from the database while another API is used to show any potential threat or accident. The mobile application is developed to provide daily commuters of railway system with real time tracking data of various trains to them. It basically fetches data (coordinates of train) from database and overlays it on a web map with the user's current position. An average rail coach has 22 meters of length and considering a 24-coach train the total length of train would be 528 meters (excluding engine). Thus RFID tags are placed on the track at an interval of 600 meters. An RFID reader is installed at the bottom of the railway engine at an appropriate height so that it can sense the RFID tags situated on the tracks. Hall sensors are placed at the bottom facing track so that it can always sense the metal track. The whole track is subdivided in some small segments and each 


\section{International Advanced Research Journal in Science, Engineering and Technology}

Vol. 6, Issue 5, May 2019

segment has been provided with a small current to make the metal track conducting. This conducting track produces magnetic field which is picked up by Hall sensor and convert this magnetic field to a suitable voltage. A track with cracks would produce a Hall voltage which is not same as that in the case of a completely safe track. If the sensed voltage is outside this threshold range then the track is considered to have cracks.

The flow chart of the operation of the system is shown in Fig. 2

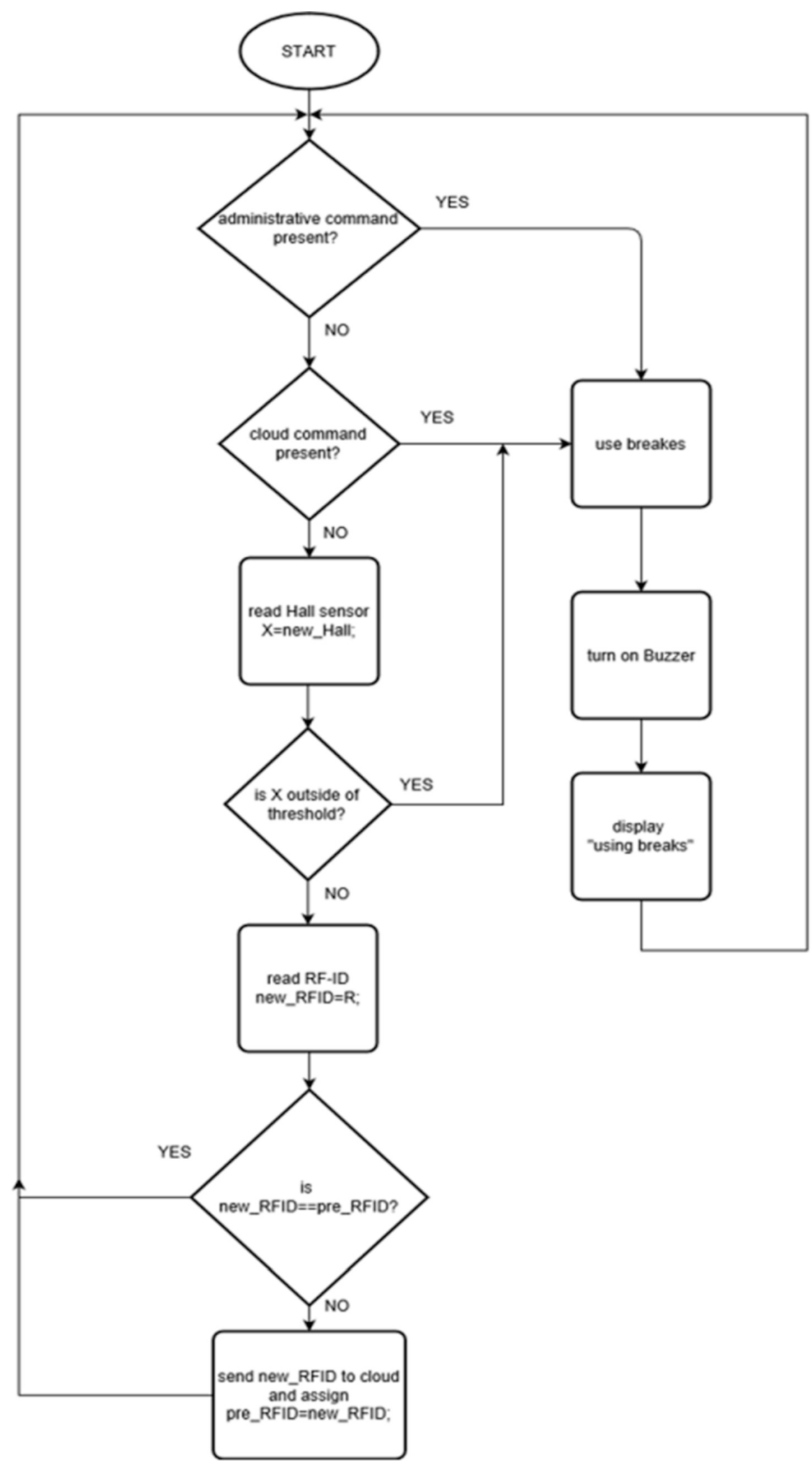

Fig .2 Flowchart of the system 


\section{International Advanced Research Journal in Science, Engineering and Technology}

Vol. 6, Issue 5, May 2019

A suitable collision avoidance algorithm has been used to provide the safety from potential threats of accidents. Data about RFID includes current RFID number, next RFID number, previous RFID number, location of the current tag, longitude and latitude of the current tag. Tags are static and RFID reader installed on the train is moving. When a train moves over a tag RFID reader reads the tag underneath the train and sends its value to cloud and updates its databases. Trains have their own table (TRAIN-table) under the same database as RFID-table. Contents of this table are train id, last updated RFID number, Status (either Safe or Not safe). When an RFID reader reads tags values and upload it database, the administrator gets to know where the train is. This RFID tag value updating also triggers the collision avoidance API which check for any possible threat of collision for the last updated train and if there is any possible threat then it updates the "Status" attribute in the TRAIN-Table. The collision avoidance API triggers when any RFID tag number get updated in TRAIN-Table. When any RFID value updates in TRAIN-Table algorithm takes the RFID number(R1) and the corresponding Train number(T1) and with gets the $\operatorname{Next}(\mathrm{N})$ and Previous(P) RFID number of Current RFID R1. The algorithm searches TRAIN-Table with $\mathrm{N}$ and P RFID numbers. If any entry in TRAIN-Table have $\mathrm{N}$ or $\mathrm{P}$ or both, then the algorithm updates "Status" attribute of all the trains which is related to R1, $\mathrm{N}$ and $\mathrm{P}$ to "Nafe" (Nafe - Not Safe). NodeMCU picks this up by data fetching and if it finds "Status" is "Nafe" then it triggers the breaking circuit based on LM293D motor driver IC.

\section{RESULTS}

In fig.3 TRAIN-Table from database is shown where "T_id" represents the train number. Each train has its own unique train number. "R_id" represents the last updated RFID tag number. The last column in the table "Status" represents the status of the train which can be either "Safe" or "Nafe". "Safe" defines that the train has no available potential threat and "Nafe" indicates that the train is approaching a potential threat. This "Nafe"status triggers the breaking circuit to stop the train. Whenever the collision detection API detects any potential threat, it updates the "Status" of this table to "Nafe"as shown in Fig.4.

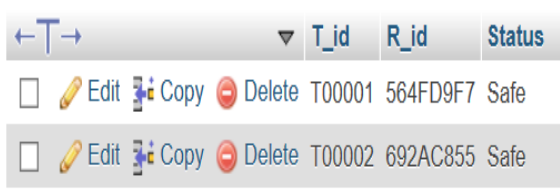

Fig. 3 TRAIN-Table from database (before collision)

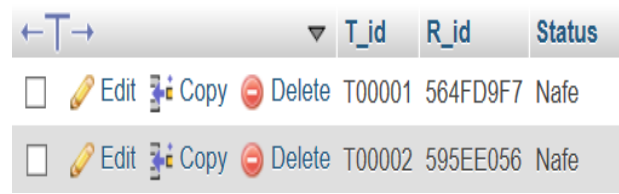

Fig. 4 TRAIN- Table from database (after collision detection)

Fig.5 shows the RFID-Table as prepared from the database. "Left"and "Right" represent the previous and next RFID tag numbers respectively. "Loc" gives the location of the "R_id" whereas "Longitude" and "Latitude" give coordinates information about "R_id". Fig. 6 shows the prototype model.

\begin{tabular}{|c|c|c|c|c|c|}
\hline$\nabla R_{-}$id & Left & Right & Loc & Longitude & Latitude \\
\hline$\square$ Edit žst Copy O Delete 19269355 & $692 A C 855$ & $36 \mathrm{~F} 90 \mathrm{AF} 8$ & 8 GAMMA & 22.5628 & 88.3417 \\
\hline$\square$ Edit j̧⿻ Copy $\odot$ Delete 36F90AF8 & 19269355 & $668 \mathrm{A08F8}$ & PHY & 22.557 & 88.3451 \\
\hline$\square$ Edit ẓ̧t Copy $\odot$ Delete 564FD9F7 & 668A08F8 & 595EE056 & 6 DELTA & 22.5412 & 88.3338 \\
\hline$\square$ Edit japt Copy $\odot$ Delete 595EE056 & & $692 A C 855$ & 5 ALPHA & 22.552 & 88.3314 \\
\hline 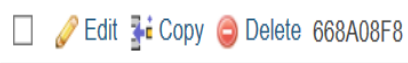 & 36F90AF8 & $564 F D 9 F 7$ & 7 CHARLIE & 22.545 & 88.3407 \\
\hline 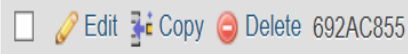 & $595 \mathrm{EE} 056$ & 19269355 & BETA & 22.5607 & 88.3344 \\
\hline
\end{tabular}

Fig. 5 RFID- Table from database

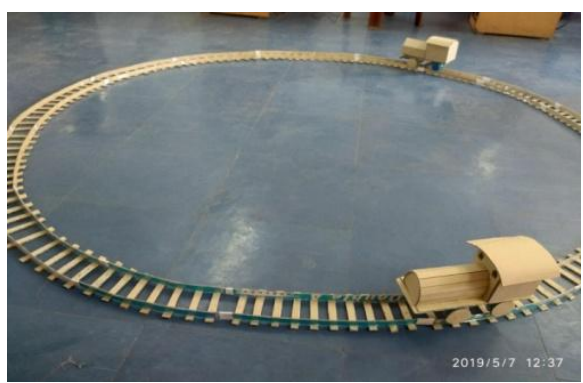

Fig. 6 Prototype model 


\title{
International Advanced Research Journal in Science, Engineering and Technology
}

\author{
Vol. 6, Issue 5, May 2019
}

\section{CONCLUSION}

In this paper an attempt has been made to make a reliable and useful automated system to provide support to railway transportation system for automatic train track monitoring and collision avoidance. The web based system uses RFID technology for collision avoidance and Hall sensors for crack detection in the railway track. The system monitors the status of all the active trains and feed the position information to the administrator. It may also feed processed data about various trains to users. It has a smart algorithm to prevent collision between trains on the same track. It also checks the condition of the tracks to ensure that no accidents happen. If this system is implemented in real life with proper precautions it may reduce the accident counts by a huge number. This also gives the train administrator effective instantaneous control over all the trains in his/her domain. The online train-tracking facility will largely improve the life style of daily commuters.

\section{REFERENCES}

[1]. K. Ajith Theja, Dr. M. Kumaresan, Dr. K. Senthil Kumar; "Automated Unmanned Railway Level Crossing System Using WSN"; International Journal of Innovative Research in Computer and Communication Engineering, Vol. 3, Issue 11, November 2015.

[2]. Any M. Kottalil, Abhijith S., Ajmal M. M., Abhilash L. J., Ajith Babu; 'Automatic Railway Gate Control System”; International Journal of Advanced Research in Electrical, Electronics and Instrumentation Engineering, Vol.3, Issue 2, February 2014.

[3]. S. R More., Ruchira Raut, Rashika K. Tandel and Snehal Yendhe; "Intelligent Railway Crossing Gate Control with High Speed Anti-Collision Alerting System"; National Conference of Role of Engineers in Nation Building (NCRENB), May 2015.

[4]. Sheikh Shanawaz Mostafa, Md. Mahbub Hossian, Khondker Jahid Reza, Gazi Maniur Rashid; "A Radio Based Intelligent Railway Grade Crossing System to Avoid Collision”, International Journal of Computer Science Issues, Vol.7, Issue 6, November 2010.

[5]. Prashantha B.Y. and Harisha S; "Smart Railway Crossing Embedded with Automated Platform Bridges"; International Journal of Research in Engineering and Technology, Vol. 4, Issue 8, August 2015.

[6]. Nisha S. Punekar, Archana A. Raut; "Improving Railway Safety with Obstacle Detection and Tracking System using GPS-GSM Model"; International Journal of Scientific and Engineering Research, Vol.4, Issue 8, August 2013.

[7]. D. Karthiga Devi, M Jeya Sudha, K.Kirthiga, N.Shanmuga Sundari: “Automatic Railway Track Obstacle Detection System"; International Journal of Informative \& Futuristic Research, Vol.3, Issue 7, March 2016. 